\title{
Breeding biology of the Crab Plover (Dromas ardeola) on the Mond Islands, northern Persian Gulf, Iran
}

\begin{abstract}
The present study describes the breeding biology of Crab Plovers (Dromas ardeola), a littleknown shorebird species nesting on Nakhilu and Omol-Karam Islands located in the Nakhilu Marine National Park in the northern Persian Gulf, Iran. This study occurred during the breeding seasons of 2009ï 2011. Colonies had between 500ї 1,500 nests and were located on sand banks $1133 \mathrm{~m}$ higher than the surrounding ground in non-overlapping areas. Burrow digging began in mid-April, and single nests were built in $2.82 \pm 0.1$ days (Range $=2 i ̈ 4$ days, $n=45$ ) in a period of $10.5 \pm 0.76$ days (Range $=8 \ddot{i} 13$ days, $n=6$ ), although a spread of digging and laying of $87.50 \pm 2.96$ days (Range $=82 i ̈ 94$ days, $n=4$ ) was recorded primarily due to renesting after human damage to the burrows. Range in nest densities was 0.14 ï 0.26 nest per $\mathrm{m} 2$. The clutch size was $1.01 \pm 0.005$ (Range $=1-2, \mathrm{n}=421)$. Egg size $(\mathrm{n}=47)$ was $64.05 \times 44.04 \mathrm{~mm}$ with an average incubation period of 33 days (Range $=31 \mathrm{ï} \mathrm{35,} \mathrm{n}=21$ ). Hatching success was $63131 \%$, with failures primarily due to egg collecting by local fishermen and tourists. An estimated of 7 weeks passed between hatching and fledging. Fledglings had almost fully developed wings (83\% of adult wing length) and feathers, but very low weight (about 55\% of adult weight) and smaller bill length (only $60 \%$ of adult bill length). A stronger control of visitors and local fishermen would benefit the breeding population of Crab Plovers on the islands.
\end{abstract}

Keyword: Breeding biology; Chick growth; Crab Plover; Dromas ardeola; Persian Gulf 